avoid possible tracheal aspiration. Elective fibreoptic oesophagogastroduodenoscopy was performed later.

Apart from a neurological cause or hysteria, total dysphagia of sudden onset is invariably caused by a bolus, itself usually secondary to underlying disease. The oesophageal lumen will usually permit the passage of the Foley catheter. If it does not, rigid oesophagoscopy should be performed under general anaesthesia. The bolus may then be removed under direct vision, and the stenosis inspected and biopsied. Further management depends on the nature of the stricture. ${ }^{5}$ Most of these patients are old and frail and need quick relief of their distressing and dangerous total dysphagia. An advantage of catheter extraction is that this can be accomplished easily, safely, and without general anaesthesia

I thank Mr J S Kirkham and Dr F J C Millard for permission to report on their patients.

1 Kelly, A B, fournal of Laryngology, Rhinology, and Otology, 1919, 34, 285. 2 Plummer, H S, Fournal of the American Medical Association, 1912, 58, 2013.

3 Tucker, G, Annals of Otology, 1939, 48, 808.

${ }^{4}$ Linscheer, W G, Lancet, 1970, 2, 1288.

${ }^{5}$ Atkinson, M, British Medical fournal, 1977, 1, 91.

(Accepted 8 December 1977)

Gastric Unit, Department of Surgery, St James' Hospital, London SW12

PETER A JONES, MB, FRCS, registrar

\section{Effect of cimetidine on absorption of oral benzylpenicillin}

The widespread use of cimetidine for treating duodenal and gastric ulcers $^{1}$ and peptic oesophagitis raises the question of possible undiscovered side effects. We investigated whether the inhibition of gastric acid secretion would affect the absorption of acid-labile drugs. Benzylpenicillin was chosen since its absorption is increased by achlorhydria. $^{2}$

\section{Subjects, methods, and results}

Five healthy volunteers, three men and two women aged 21-30 years and weighing 59-87 kg, were studied. After an overnight fast $600 \mathrm{mg}$ sodium benzylpenicillin in $100 \mathrm{ml}$ water was administered. Venous blood samples were taken every 15 minutes and urine collected hourly for six hours. Free fluids were allowed after four hours. The experiment was repeated after 24 hours of cimetidine treatment using $1000 \mathrm{mg} /$ day plus $400 \mathrm{mg}$ one hour before the penicillin. Serum and urine samples were assayed in duplicate using the conventional agar plate diffusion method.

Blood penicillin concentrations followed a similar curve in all five subjects, with peak levels of $1.08-2.45 \mathrm{mg} / \mathrm{l}$ (mean $( \pm S D) 1.93 \pm 0.54 \mathrm{mg} / \mathrm{l}$ ) between 30 and 90 minutes. By four hours the serum concentrations had fallen to a mean of $0.16+0.21 \mathrm{mg} / \mathrm{l}$. Over six hours $24.1 \mathrm{mg}$ to $78.9 \mathrm{mg}$ of penicillin was excreted in the urine, over $80 \%$ in the first four hours.

After cimetidine the peak serum penicillin concentration in one subject increased from $1.8 \mathrm{mg} / 1$ to $4.1 \mathrm{mg} / 1$ and $6.0 \mathrm{mg} / 1$ on repeating the experiment. The concentration at four hours was three times the control value. Urinary penicillin excretion (see figure) showed an eightfold rise from $49.4 \mathrm{mg}$ to $386.3 \mathrm{mg}$ after cimetidine, and $417.3 \mathrm{mg}$ on repetition. In four subjecis no significant increase in absorption occurred, although the mean serum concentration at four hours was slightly increased $(0.55 \pm 0.32 \mathrm{mg} / \mathrm{l})$. The peak serum penicillin concentrations on cimetidine were $1.55-2.60 \mathrm{mg} / \mathrm{l}$, and urinary excretion was $27 \cdot 3-73.5 \mathrm{mg}$.

\section{Comment}

The absorption of penicillin has been shown to be largely unchanged in most subjects given oral cimetidine. Gastric juice at pH 2 rapidly destroys benzylpenicillin. ${ }^{2}$ In most subjects given cimetidine the $\mathrm{pH}$ of gastric juice remains below 3 while fasting, since the drug diminishes the volume of gastric juice ${ }^{3}$ as well as the basal and maximal acid secretions. ${ }^{4} \mathrm{~A}$ few subjects have transient achlorhydria after oral cimetidine, and in these increased absorption of penicillin

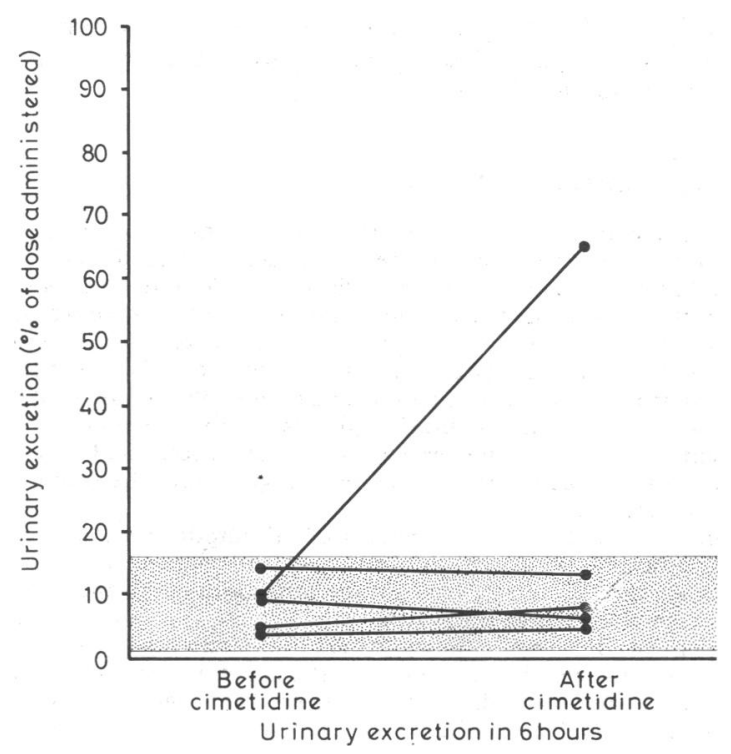

Urinary excretion of benzylpenicillin before and after cimetidine. Shaded area represents mean value \pm 2 SD before cimetidine.

would be predicted, similar to that in the newborn and in pernicious anaemia. $^{2}$ This would seem the likely explanation for the large increase in penicillin absorption in one subject after cimetidine. A sparing effect of cimetidine on orally administered pancreatic enzymes has recently been shown in chronic pancreatitis, ${ }^{5}$ but in this study the gastric $\mathrm{pH}$ was also increased by the buffering effect of a meal.

Increased absorption of acid-labile substances is a predictable side effect in some patients taking cimetidine, and this should be kept in mind when other drugs are given concurrently.

We wish to thank the doctors and medical students who volunteered as subjects for this study.

${ }^{1}$ Frost, F, et al, British Medical fournal, 1977, 2, 795.

${ }^{2}$ Goodman, L S, and Gilman, A, The Pharmacological Basis of Therapeutics, 5 th edn. New York, Macmillan, 1975.

${ }^{3}$ Burland, W L, et al, British fournal of Clinical Pharmacology, 1975, 2, 481

${ }^{4}$ Pounder, R E, et al, Gut, 1976, 17, 133.

5 Regan, P T, et al, New England fournal of Medicine, 1977, 297, 854.

(Accepted 6 December 1977)

Department of Medicine, Middlesex Hospital, London W1N 8AA

A J FAIRFAX, BSC, MRCP, registrar (present address: Department of Medicine, Brompton Hospital, London SW3 6HP)

$\mathrm{J}$ ADAM, MB, BS, house officer

Department of Microbiology, Middlesex Hospital, London W1N 8AA

F S PAGAN, BA, MB, lecturer (present address: Department of Microbiology, Darlington Memorial Hospital, Darlington, Co Durham)

\section{Haemodialysis during cyclophosphamide treatment}

The administration of cytotoxic drugs to patients with lymphomas with inadequate renal function is an uncommon problem, but may become more frequent with an increasing incidence of renal complications owing to improved survival. In patients on haemodialysis, drugs such as cyclophosphamide that are not rapidly cleared from the plasma may be removed in the dialysate, resulting in a reduced therapeutic effect. We report details of a patient receiving intermittent courses of intravenous cyclophosphamide and vincristine with oral prednisone while being treated with haemodialysis, in whom cyclophosphamide concentrations were measured in the plasma and dialysate. 


\section{Case report}

A 27-year-old man who had been diagnosed five years previously as having chronic glomerulonephritis, and was subsequently maintained on haemodialysis at home, presented with an enlarged left inguinal lymph node. On biopsy and further investigation he was found to have stage IV malignant lymphoma of diffuse histiocytic type. Despite histological evidence of liver disease the results of standard liver function tests were normal.

The first dose of intravenous cyclophosphamide $(600 \mathrm{mg})$ was administered five minutes before haemodialysis was started and subsequently samples of plasma and dialysate were taken. Dialysis was maintained for six hours using a forearm arteriovenous fistula and a Gambro 1 square metre dialyser. Cyclophosphamide concentrations were measured by mass spectrometrystable isotope dilution using tetradeuterated cyclophosphamide as an internal standard. The procedure was identical with that described ${ }^{1}$ except that whole blood samples were centrifuged as taken and addition to citrate saline was omitted. After addition of the deuterated cyclophosphamide, plasma and dialysate were extracted with ethyl acetate. Cyclophosphamide concentrations in plasma and dialysate were plotted on semi-log paper (see fig). A half life of $2 \mathrm{~h} 35 \mathrm{~min}$ was found for plasma clearance of the drug.

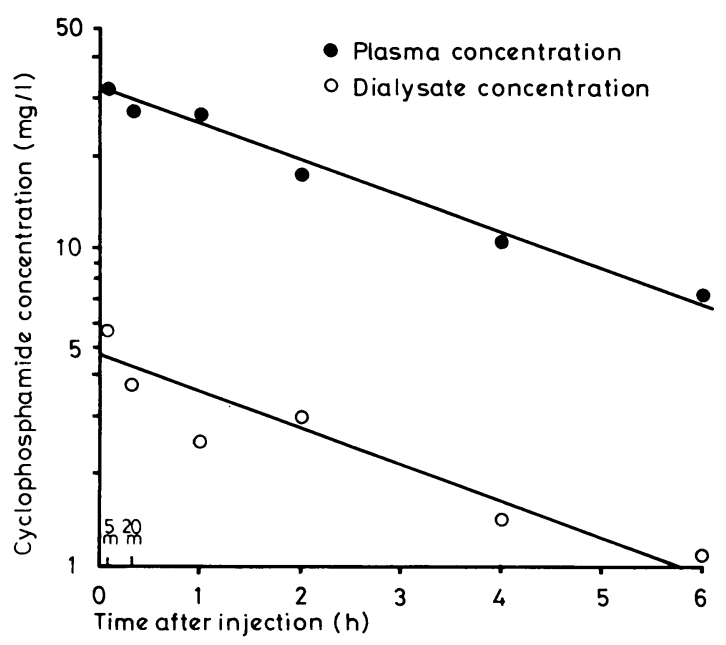

Cyclophosphamide concentrations in plasma and dialysate after $600-\mathrm{mg}$ injection.

\section{Comment}

Cyclophosphamide is a widely used bifunctional alkylating agent, which undergoes biotransformation in the liver to form an active metabolite. ${ }^{2}$ The plasma half life shows considerable interpatient variation $(1 \cdot 8-9 \cdot 2 \mathrm{~h}){ }^{3}$ It has been suggested ${ }^{4}$ that the rate of disappearance of unchanged drug is predominantly determined by the rate of its biotransformation in the liver. In our patient both plasma concentrations ${ }^{1}$ and half life $^{3}$ for cyclophosphamide are within the range found for patients with normal renal function. The earlier study cited $^{3}$ also included one patient with renal impairment, who had a normal plasma half life. The present results show that little cyclophosphamide is lost in the dialysate, the concentrations being an order of magnitude lower than plasma concentrations. On the basis of our results, therefore, haemodialysis need not be interrupted during treatment with cyclophosphamide.

We are grateful to Dr T J McElwain, Dr A J Eisinger, and Dr D G Davidson for their help in preparing this paper.

1 Jarman, M, et al, Clinica Chimica Acta, 1975, 58, 61.

2 Brock, N, and Hohorst, H J, Arzneimittel-Forschung, 1963, 13, 1021.

3 Bagley, C M, Bostick, F W, and De Vita, V T, jun, Cancer Research, 1973, 33, 226 .

${ }^{4}$ Mouridsen, H T, Faber, O, and Skovsted, L, Acta Pharmacologica et Toxicologica, 1974, 35, 98.

(Accepted 8 December 1977)

Divisions of Chemistry and Medicine, Institute of Cancer Research, Sutton, Surrey

R A V MILSTED, MB, MRCP, Hamilton Fairley research fellow $M$ JARMAN, MA, PHD, member of scientific staff

\section{Apathetic hyperthyroidism with hypomagnesaemia and raised alkaline phosphatase concentration}

Thyrotoxicosis may exist in two forms: the well-recognised hyperkinetic hyperthyroidism, and apathetic thyrotoxicosis, described by Lahey in $1931 .{ }^{1}$ In the latter form patients present with wrinkled and pigmented facies and with severe weight loss and apathy. They have the typical demeanour of hypothyroidism. Fairclough and Besser $1974^{2}$ reported a case of apathetic hyperthyroidism with a normal T4 yet raised T3 concentration. We describe two patients with apathetic hypothyroidism and appreciable hypomagnesaemia.

\section{Case reports}

Case 1-A 36-year-old unmarried woman complained of chronic anxiety, palpitations, and weight loss. She was prescribed diazepam (Valium), $5 \mathrm{mg}$ thrice daily, and three years later realised that she was continually tired and unable to work properly. She had lost $19 \mathrm{~kg}$ in weight and noticed pigmentation on her skin; she had had no diarrhoea. Examination confirmed the pigmentation, and showed her pulse rate to be 60 per minute; she had evidence of a proximal myopathy and also generalised weakness; the thyroid gland was just palpable. The results of investigations were normal save for serum concentrations of magnesium of $0.34 \mathrm{mmol} / 1(0.83 \mathrm{mg} / 100 \mathrm{ml})$, of alkaline phosphatase of $194 \mathrm{IU} / \mathrm{l}$, and of thyroxine of $220 \mathrm{mmol} / 1(17 \cdot 1 \mu \mathrm{g} /$ $100 \mathrm{ml}$ ). She had no radiological bone disease. Carbimazole (Neomercazole), $10 \mathrm{mg}$ thrice daily, was started and one month later her serum alkaline phosphatase concentration was $140 \mathrm{IU} / 1$ and magnesium $0.46 \mathrm{mmol} / \mathrm{l}$ $(1.12 \mathrm{mg} / 100 \mathrm{ml})$. After two months' treatment the respective values were $104 \mathrm{IU} / 1$ and $0.59 \mathrm{mmol} / \mathrm{l}(1.43 \mathrm{mg} / 100 \mathrm{ml})$, and after three months $80 \mathrm{IU} / \mathrm{l}$ and $0.85 \mathrm{mmol} / 1(2.1 \mathrm{mg} / 100 \mathrm{ml})$, both normal. She was much improved clinically, having lost her anxiety, gained $7 \mathrm{~kg}$, and had adequate energy.

Case 2-A 32-year-old unmarried woman complained of weight loss of $19 \mathrm{~kg}$, and increased sweating. She disliked hot weather. Her serum thyroxine concentration was $194 \mathrm{nmol} / 1(15 \cdot 1 \mu \mathrm{g} / 100 \mathrm{ml})$. She was treated with carbimazole, $15 \mathrm{mg}$ thrice daily, and then lost to follow-up for six years. During this period she took no treatment and presented again with pigmentation and slowness in her movements, but no diarrhoea. She had an obvious lack of energy; her pulse rate was 60 and she had the appearances of hypothyroidism save for her thinness. The thyroid gland was palpable and soft. The serum concentrations were: thyroxine $207 \mathrm{nmol} / 1(16 \cdot 1 \mu \mathrm{g} / 100 \mathrm{ml})$, magnesium $0.41 \mathrm{mmol} / 1(0.99 \mathrm{mg} / 100 \mathrm{ml})$, and alkaline phosphatase 234 IU/l. She had no radiological bone disease. After one month's treatment with carbimazole, $15 \mathrm{mg}$ thrice daily, she felt better, and the serum concentrations of magnesium had risen to $0.52 \mathrm{mmol} / 1(1.3 \mathrm{mg} / 100 \mathrm{ml})$ and of alkaline phosphatase had fallen to $170 \mathrm{IU} / 1$. The respective concentrations after two months were $0.65 \mathrm{mmol} / 1(1.6 \mathrm{mg} / 100 \mathrm{ml})$ and $120 \mathrm{IU} / \mathrm{l}$, and after three months' treatment (when she had adequate energy and felt well), 0.85 $\mathrm{mmol} / \mathrm{l}(2 \cdot 1 \mathrm{mg} / 100 \mathrm{ml})$ and $65 \mathrm{IU} / \mathrm{l}$. She has remained well for two years.

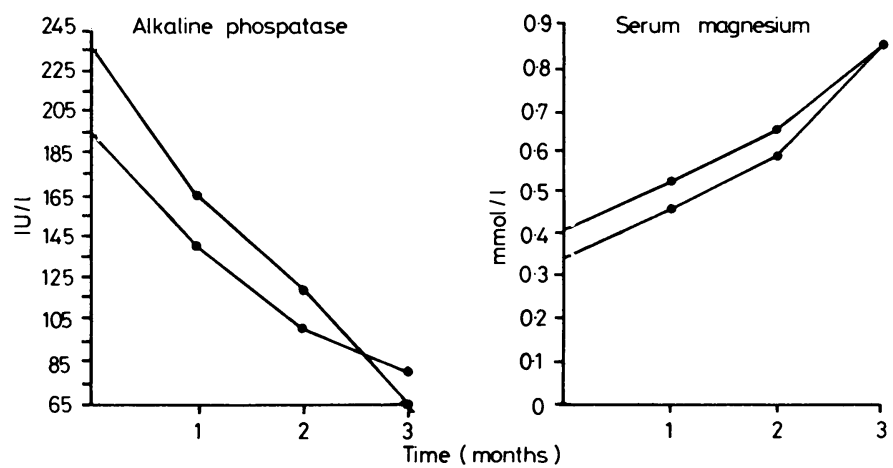

Serum magnesium concentrations after carbimazole treatment for thyrotoxicosis was begun.

Conversion: SI to traditional units-Magnesium: $1 \mathrm{mnol} / 1 \approx 2.4 \mathrm{mg} / 100 \mathrm{ml}$.

\section{Discussion}

Thyroxine causes mitochondrial swelling, ${ }^{3}$ resulting in loss of magnesium from the mitochondrion and hypomagnesaemia. This hypomagnesaemia is postulated as producing the apathetic form of hyperthyroidism, Neguib ${ }^{4}$ claiming that thyrotoxic patients have shown an increase in muscular strength after treatment with magnesium chloride. Thyroxine is alone responsible for the induction of enzymes, such as glutamate dehydrogenase, ${ }^{3}$ and similarly it regulates the induction of alkaline phosphatase in osteoblasts and to a lesser 